\title{
Portal inflow reconstruction for liver transplantation with portal vein thrombosis
}

\author{
Zhe Yang ${ }^{1}$, Shuo Wang ${ }^{1}$, Jan Lerut ${ }^{2}$, Li Zhuang ${ }^{1}$, Shusen Zheng ${ }^{1,3}$ \\ ${ }^{1}$ Department of Hepatobiliary and Pancreatic Surgery, Department of Liver Transplantation, Shulan (Hangzhou) Hospital, Zhejiang Shuren \\ University School of Medicine, Hangzhou, China; ${ }^{2}$ Starzl Unit of Abdominal Transplantation, University Hospitals Saint Luc, Université catholique \\ Louvain, Brussels, Belgium; ${ }^{3}$ National Clinical Research Center of Infectious Diseases, Hangzhou, China \\ Correspondence to: Prof. Shusen Zheng. Department of Hepatobiliary and Pancreatic Surgery, Department of Liver Transplantation, Shulan (Hangzhou) \\ Hospital, Zhejiang Shuren University School of Medicine, 848 Dongxin Road, Hangzhou 310022, China. Email: shusenzheng@zju.edu.cn.
}

Submitted Nov 14, 2020. Accepted for publication Feb 02, 2021.

doi: 10.21037/hbsn-20-797

View this article at: http://dx.doi.org/10.21037/hbsn-20-797

Complex non-malignant portal vein thrombosis (PVT), defined as Yerdel grade 4, was previously considered as a contraindication for liver transplantation (LT) because of technical challenges followed by high morbidity and mortality (1). In complex PVT, Bhangui et al. proposed defining reconstruction of portal inflow as physiological when the splanchnic venous blood can be redirected to the graft, thus resolving the pre-existing portal hypertension (PHT) (2). Renoportal anastomosis (RPA) and coronaryportal anastomosis (CPA) are 2 main options (3). However, all reports were single case reports or small case series regarding physiological reconstruction for complex PVT, therefore, the postoperative outcomes were very heterogeneous. Herein, we introduced our experience of physiological portal inflow restoration for liver transplant in complex PVT patients, and outcomes were compared with those of patients with non-complex PVT.

This study enrolled 38 consecutive patients with PVT transplanted during the period of July 2017 to June 2020 in our center. This study was conducted with the approval of the institutional review board and ethics committee and conformed to the Declaration of Helsinki. Informed consent was obtained from each patient. Patients with Yerdel grade 4 PVT were grouped as "complex PVT" (n=16) and less severe PVT (Yerdel grade 1-3) were classified as "non-complex PVT" (n=22). Patient characteristics and correlation with grade of PVT were shown in Table 1. Compared with non-complex PVT group, complex PVT group had longer operative time (366.06 vs. 311.77 minutes, $\mathrm{P}=0.038$ ), more red blood cell transfusion (8.97 vs. 3.93 unites, $\mathrm{P}=0.002$ ), higher postoperative anastomotic stricture rates $(25 \%$ vs. $4.5 \%, \mathrm{P}=0.066)$ and lower overall survival (OS) rate $(81.3 \%$ vs. $100 \%, \mathrm{P}=0.034)$. Patient survival rates at 1 and 2 years in the complex PVT group and noncomplex PVT group were $81.3 \%, 81.3 \%$ and $100 \%, 100 \%$, respectively $(\mathrm{P}=0.036$, Figure $\mathrm{S} 1 \mathrm{~A})$. By excluding death not related to surgical complication, patient survival was both $100 \%$ of the 2 groups. Non-PHT related postoperative complication adversely affect patient survival. Patients with non-PHT related postoperative complication has significantly inferior 1,2 , and 3 years OS than those without (78.6\%, $78.6 \%, 78.6 \%$ vs. $100 \%, 100 \%, 100 \%, \mathrm{P}=0.018$, Figure S1B). In addition, no significant difference was observed between complex and non-complex PVT patients in terms of liver function recovery, except for the change of alanine aminotransferase in the early phase after LT. No postoperative kidney injury was observed in patients with complex PVT (Figure S2).

Operative details and postoperative course of the patients with complex PVT are summarized in Table S1. Diffuse PVT and the presence of any patent collaterality were confirmed in all cases, and therefore physiological portal inflow to the graft was feasible. Among 16 patients, 7 patients had large left gastric vein (LGV) and CPA was performed. Three patients had significant splenorenal shunt (SRS) ( $>8 \mathrm{~mm}, 1$ surgical and 2 spontaneous) and received RPA. Enlarged pericholedochal varix, splenic vein (SV) or distal superior mesenteric vein (DSMV) were observed in 3 patients, and thus pericholedochal varix to portal vein anastomosis, splenic-portal anastomosis (SPA) or DSMV- 
Table 1 Patient characteristics and correlation with grade of non-malignant PVT

\begin{tabular}{|c|c|c|c|}
\hline Variables & \multicolumn{3}{|c|}{ Grade of PVT } \\
\hline \multicolumn{4}{|l|}{ Pre-LT characteristics } \\
\hline Male, gender, n (\%) & $17(77.3)$ & $11(68.8)$ & 0.556 \\
\hline Age, $>50$ years, $n(\%)$ & $16(72.7)$ & $10(62.5)$ & 0.503 \\
\hline Child score at LT, C, n (\%) & $11(50.0)$ & $9(56.3)$ & 0.816 \\
\hline Pre-LT operation, n (\%) & $7(31.8)$ & $6(37.5)$ & 0.715 \\
\hline Pre-LT variceal bleeding, n (\%) & $11(50.0)$ & $5(31.3)$ & 0.248 \\
\hline Pre-LT ascites, n (\%) & $20(90.9)$ & $15(93.8)$ & 0.748 \\
\hline \multicolumn{4}{|l|}{ Surgical characteristics } \\
\hline Portal anastomosis, PPA, n (\%) & $22(100.0)$ & $0(0.0)$ & $<0.001$ \\
\hline Interposed graft, n (\%) & $0(0.0)$ & $7(43.8)$ & 0.001 \\
\hline Operative time (min) (mean, SD) & $311.77(81.03)$ & 366.06 (70.36) & 0.038 \\
\hline Anhepatic time (min) (mean, SD) & $73.36(33.98)$ & $85.31(47.55)$ & 0.372 \\
\hline Estimated blood loss (mL) (mean, SD) & $1,769.55(1430.29)$ & 2,225 (870.63) & 0.267 \\
\hline RBC transfusion (units) (mean, SD) & $3.93(3.82)$ & $8.97(5.63)$ & 0.002 \\
\hline Fresh frozen plasma (ml) (mean, SD) & $983.18(376.2)$ & 1,118.13 (330.62) & 0.259 \\
\hline $\begin{array}{l}\text { Survival after excluding death not related to surgical } \\
\text { complication, } \mathrm{n}(\%)\end{array}$ & $22(100.0)$ & $16(100.0)$ & 1.000 \\
\hline Overall Survival, n (\%) & $22(100.0)$ & $13(81.3)$ & 0.034 \\
\hline
\end{tabular}

a, Chi-square test. PVT, portal vein thrombosis; LT, liver transplantation; HBV, hepatitis B virus; PPA, porto-portal anastomosis; SD, standard deviation.

portal anastomosis was performed. One patient had patent SRS/SV and received RPA and SPA simultaneously (Figure S3). One patient had large SRS/LGV and received RPA and CPA (Figure S4). One patient had patent SRS/ inferior mesenteric vein (IMV) and received RPA and IMV-portal anastomosis (IPA). A jump graft was used in 7 cases $(43.8 \%)$. Portal anastomotic thrombosis and stricture was observed in 4 patients (25\%), successfully resolved by percutaneous thrombolysis and stenting. No complications related to PHT occurred in the postoperative period. The most common non-PHT-related complication was biliary anastomotic stenosis (4/16 patients, $25 \%$ ), and were improved with interventional therapy. One patient died at 29 days due to graft versus host disease (GVHD), 1 patient at 107 days due to pulmonary hypertension, and 1 patient at 57 days due to sepsis. There was no portal vein-related 
morbidity. At last follow-up, 13 surviving patients had no signs of PHT and patent anastomoses on Doppler US and CT angiography.

The novel proposed classification of non-malignant PVT, incorporating functional/haemodynamic parameters, was directed towards surgical decision-making. We proposed flowchart for the management of complex portal vein thrombosis in LT as shown in Figure S5. In patients with complex PVT, a pre-existing patent portosystemic shunt (spontaneous or surgical) was mandatory to ameliorate PHT and achieve physiological reconstruction from a functional standpoint $(4,5)$. Physiological RPAs could be considered as an option in case of extensive splanchnic vein thrombosis and large splenorenal shunt (6). Anastomosis of a large LGV to the graft portal vein was another optimal choice and $92 \%$ patients were well with a patent portal inflow (2). Other varices (such as pericholedochal varix, right superior colic vein, or ileocolic vein) also can be used to reconstruct the portal inflow to the graft (2). In line with our data, posttransplant anastomotic stenosis and thrombosis were the main concerns, however, over $80 \%$ were alive and well with patent portal inflow after medical or interventional therapy $(7,8)$.

In conclusion, although technically demanding, tailored non-anatomical, physiological reconstructions can be performed safely and effectively as a life-saving procedure for patients with complex PVT, allowing similar outcomes as those patients without complex PVT.

\section{Acknowledgments}

We express our gratitude to Qi-Yong Li, Guo-Ping Jiang, Jian-Peng Liu, Kai Wun Chang, Xiao Xu for their help in collecting patient information and manuscript revision.

Funding: This study was supported by the National S\&T Major Project (2017ZX10203205), the Medical Science and Technology Project of Zhejiang Province (2014KYA082) and the Natural Science Foundation of Zhejiang Province (LY21H160055).

\section{Footnote}

Provenance and Peer Review: This article was a standard submission to the journal. The article has undergone external peer review.

Conflicts of Interest: All authors have completed the ICMJE uniform disclosure form (available at https://hbsn. amegroups.com/article/view/10.21037/hbsn-20-797/coif). The authors have no conflicts of interest to declare.

Ethical Statement: The authors are accountable for all aspects of the work in ensuring that questions related to the accuracy or integrity of any part of the work are appropriately investigated and resolved. The study was conducted in accordance with the Declaration of Helsinki (as revised in 2013). The study was approved by Institutional Ethics Committee of Shulan (Hangzhou) Hospital (NO.: 870 ) and individual consent for this retrospective analysis was waived.

Open Access Statement: This is an Open Access article distributed in accordance with the Creative Commons Attribution-NonCommercial-NoDerivs 4.0 International License (CC BY-NC-ND 4.0), which permits the noncommercial replication and distribution of the article with the strict proviso that no changes or edits are made and the original work is properly cited (including links to both the formal publication through the relevant DOI and the license). See: https://creativecommons.org/licenses/by-nc-nd/4.0/.

\section{References}

1. Yerdel MA, Gunson B, Mirza D, et al. Portal vein thrombosis in adults undergoing liver transplantation: risk factors, screening, management, and outcome. Transplantation 2000;69:1873-81.

2. Bhangui P, Lim C, Levesque E, et al. Novel classification of non-malignant portal vein thrombosis: A guide to surgical decision-making during liver transplantation. J Hepatol 2019;71:1038-50.

3. Teng F, Sun KY, Fu ZR. Tailored classification of portal vein thrombosis for liver transplantation: Focus on strategies for portal vein inflow reconstruction. World J Gastroenterol 2020;26:2691-701.

4. Bhangui P, Lim C, Salloum C, et al. Caval inflow to the graft for liver transplantation in patients with diffuse portal vein thrombosis: a 12-year experience. Ann Surg 2011;254:1008-16.

5. Bhangui P, Fernandes ESM, Di Benedetto F, et al. Current management of portal vein thrombosis in liver transplantation. Int J Surg 2020;82s:122-7.

6. Kisaoglu A, Demiryilmaz I, Dandin O, et al. Renoportal anastomosis in living donor liver transplantation. Hippokratia 2019;23:140-2.

7. Sharshar M, Yagi S, Iida T, et al. Liver transplantation 
in patients with portal vein thrombosis: A strategic road map throughout management. Surgery 2020;26:S00396060(20)30467-0.

8. Ozer A, Aktas H, Yilmaz TU, et al. Liver Transplant in
Patients With Portal Vein Thrombosis: The Experience of 55 Patients. Exp Clin Transplant 2019. [Epub ahead of print]. doi: 10.6002/ect.2018.0260.

Cite this article as: Yang Z, Wang S, Lerut J, Zhuang L, Zheng S. Portal inflow reconstruction for liver transplantation with portal vein thrombosis. HepatoBiliary Surg Nutr 2021;10(2):291-294. doi: 10.21037/hbsn-20-797 

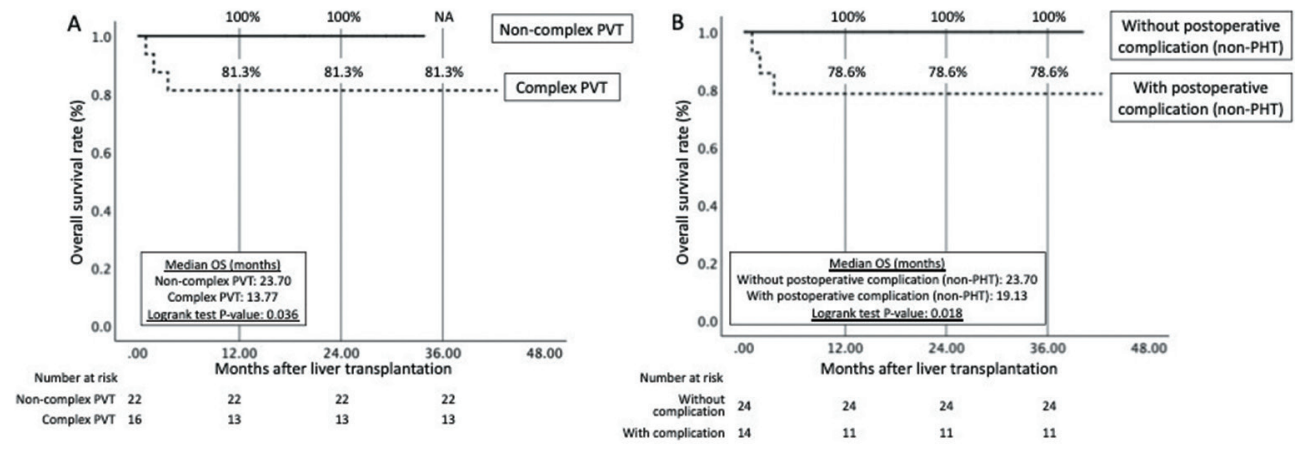

Figure S1 Outcome of patients with PVT who underwent LT. (A) Kaplan-Meier OS after LT for patients with complex PVT and noncomplex PVT. (B) The correlation between non-PHT related postoperative complications with OS after LT. PVT, portal vein thrombosis; LT, liver transplantation; OS, overall survival; PHT, portal hypertension.
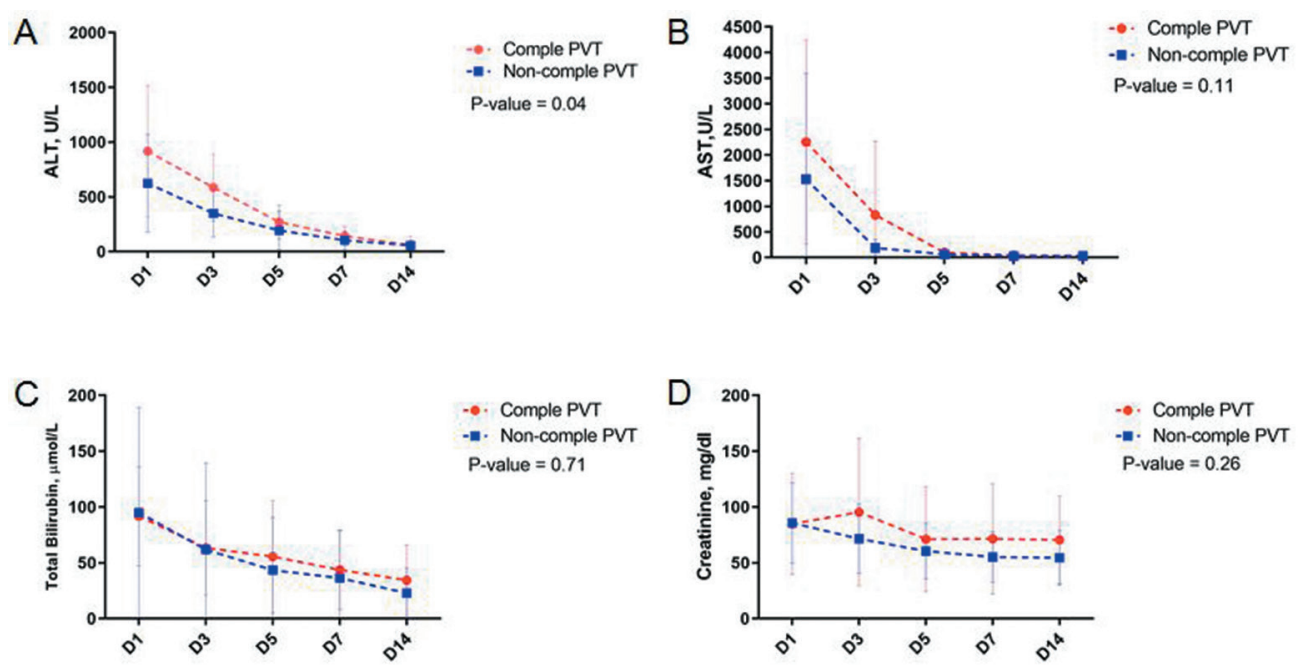

Figure S2 Dynamic changes of liver function and renal function on day 1, 3, 5, 7, 14 after LT. (A) ALT level. (B) AST level. (C) Total bilirubin level. (D) Creatinine level. LT, liver transplantation; PVT, portal vein thrombosis; ALT, alanine aminotransferase; AST, aspartate aminotransferase. 

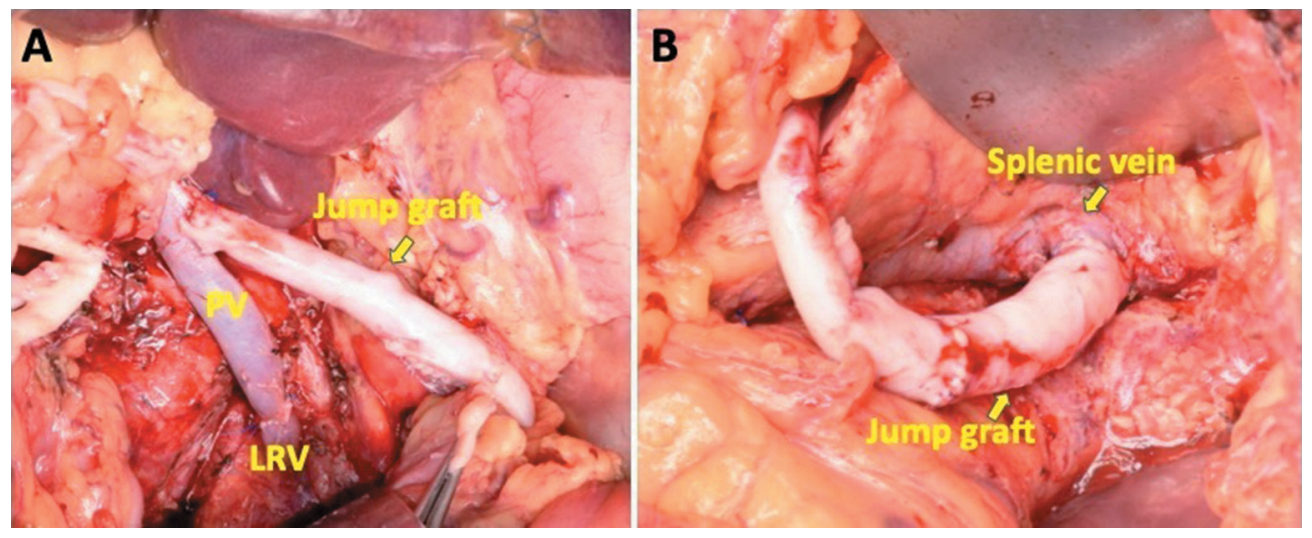

Figure S3 Patient who received RPA and SPA simultaneously. (A) renoportal anastomosis. (B) portal vein and splenic vein anastomosis. RPA, renoportal anastomosis; SPA, splenic-portal anastomosis; PV, portal vein; LRV, left renal vein.

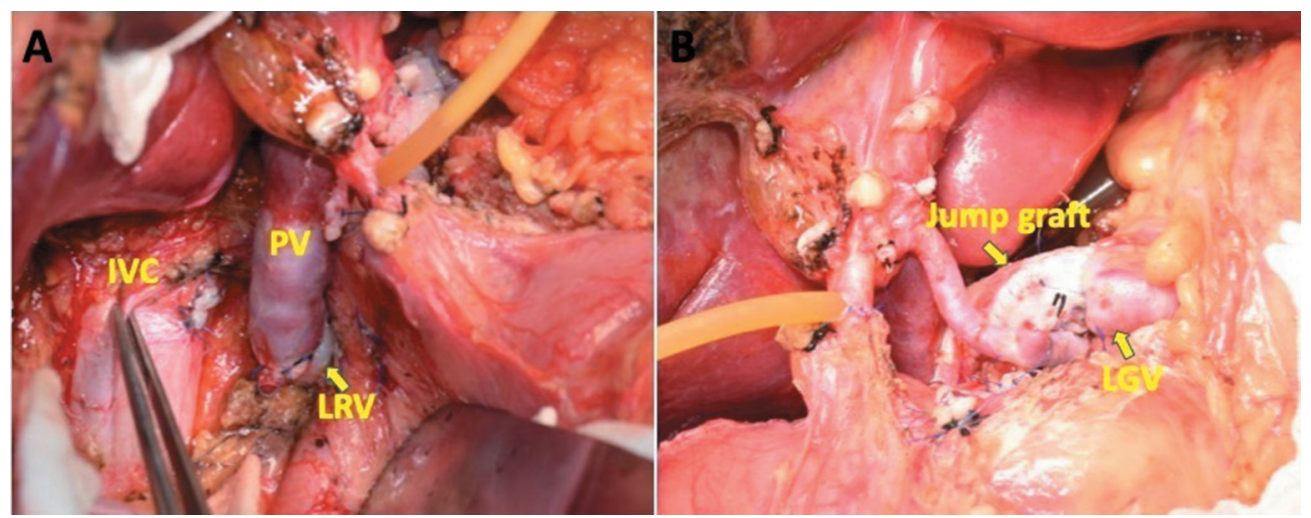

Figure S4 Patient who received RPA and CPA simultaneously. (A) renoportal anastomosis. (B) coronary-portal anastomosis. RPA, renoportal anastomosis; CPA, coronary-portal anastomosis; PV, portal vein; LRV, left renal vein; LGV, left gastric vein; IVC, inferior vena cava.

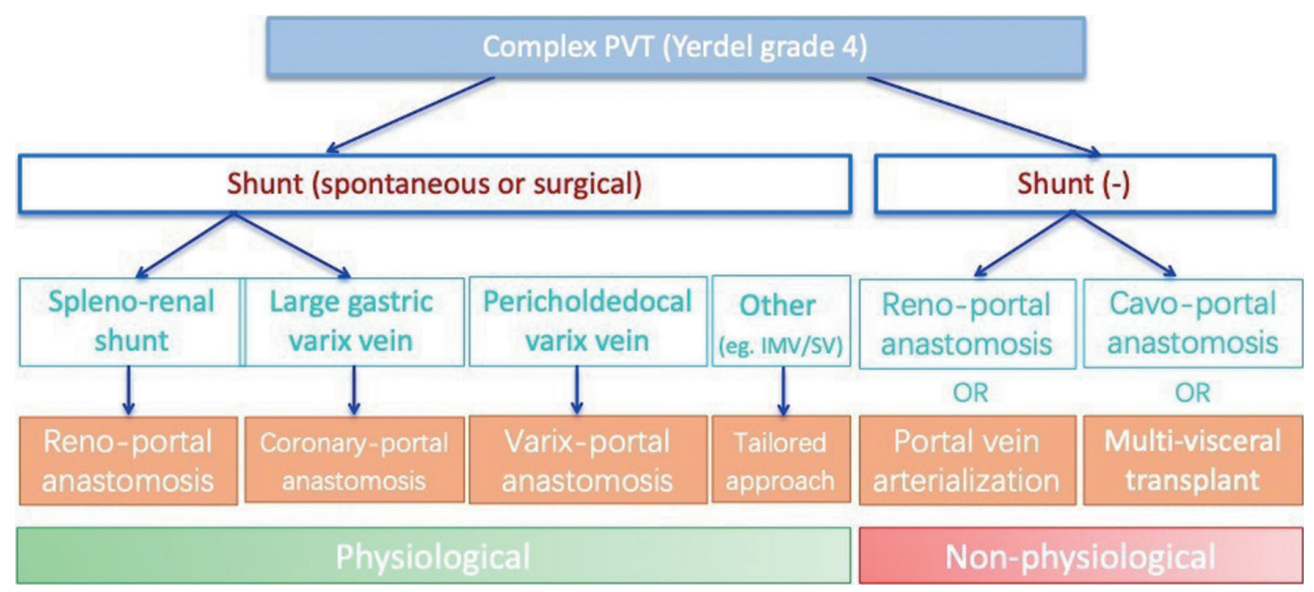

Figure S5 Proposed flowchart for the management of complex portal vein thrombosis in liver transplantation. 
Table S1 Operative details and postoperative course of patients with complex PVT

\begin{tabular}{|c|c|c|c|c|c|c|c|c|c|c|c|c|}
\hline Patient no. & PVT grade & Sex/age (yr) & $\begin{array}{c}\text { Pretransplant } \\
\text { portosystemic shunt }\end{array}$ & Portal reconstruction & Interposed graft & Operative time (minutes) & $\begin{array}{l}\text { RBC transfusion } \\
\text { (units) }\end{array}$ & Anastomotic thrombosis & Anastomotic stricture & $\begin{array}{l}\text { Postoperative complication } \\
\text { related to PHT }\end{array}$ & $\begin{array}{l}\text { Postoperative complication } \\
\text { not related to PHT }\end{array}$ & Outcome/OS (m) \\
\hline 1 & Yerdel 4 & $\mathrm{M} / 59$ & LGV & CPA & None & 285 & 9 & None & None & None & GVHD & Died due to GVHD/0.97 m \\
\hline 2 & Yerdel 4 & $\mathrm{M} / 46$ & LGV & CPA & Yes & 410 & 9 & None & None & None & None & Alive/25.1 m \\
\hline 3 & Yerdel 4 & $F / 53$ & LGV & CPA & None & 240 & 7 & None & None & None & Biliary stenosis & Alive/42.4 m \\
\hline 4 & Yerdel 4 & $F / 53$ & LGV & CPA & None & 382 & 14 & None & None & None & None & Alive/32.6 m \\
\hline 5 & Yerdel 4 & $\mathrm{M} / 56$ & LGV & CPA & None & 320 & 18 & None & None & None & Pulmonary hypertension & $\begin{array}{l}\text { Died due to pulmonary } \\
\text { hypertension/3.6 m }\end{array}$ \\
\hline 6 & Yerdel 4 & $\mathrm{M} / 34$ & LGV & CPA & None & 411 & 11 & None & None & None & None & Alive/40.2 m \\
\hline 7 & Yerdel 4 & $\mathrm{M} / 53$ & LGV & CPA & None & 292 & 10 & None & Yes & None & Biliary bleeding & Alive/10.3 m \\
\hline 8 & Yerdel 4 & $\mathrm{M} / 53$ & pericholedochal varix & $\begin{array}{l}\text { pericholedochal varix to } \\
\text { portal anastomosis }\end{array}$ & None & 360 & 0 & None & None & None & None & Alive/23.6 m \\
\hline 9 & Yerdel 4 & $\mathrm{M} / 50$ & sv & SPA & Yes & 515 & 13 & None & None & None & Biliary stenosis & Alive/13.8 m \\
\hline 10 & Yerdel 4 & $F / 32$ & DSMV & $\begin{array}{l}\text { DSMV to portal } \\
\text { anastomosis }\end{array}$ & Yes & 426 & 12 & None & Yes & None & Biliary stenosis & Alive/16.1 m \\
\hline 11 & Yerdel 4 & $\mathrm{M} / 52$ & SRS, SV & RPA and SPA & Yes & 375 & 2 & None & None & None & None & Alive/11.1 m \\
\hline 12 & Yerdel 4 & $F / 17$ & SRS & RPA & None & 319 & 6 & None & Yes & None & None & Alive $/ 7.0 \mathrm{~m}$ \\
\hline 13 & Yerdel 4 & $\mathrm{M} / 39$ & SRS & RPA & Yes & 380 & 0 & None & None & None & None & Alive/14.1 m \\
\hline 14 & Yerdel 4 & $\mathrm{~F} / 50$ & SRS, LGV & RPA and CPA & Yes & 427 & 14 & Yes & Yes & None & None & Alive/8.6 m \\
\hline 16 & Yerdel 4 & $\mathrm{M} / 55$ & SRS & RPA & None & 420 & 18 & None & None & None & $\begin{array}{l}\text { Biliary stenosis and } \\
\text { infection }\end{array}$ & Died due to infection/1.9 m \\
\hline
\end{tabular}

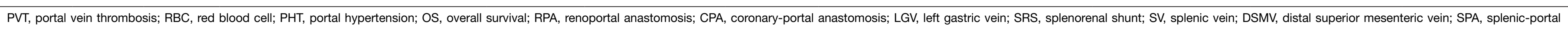
anastomosis; IMV, inferior mesenteric vein; IPA, IMV-portal anastomosis; GVHD, graft versus host disease. 